\title{
Hydrogen Sulfide: An Endogenous Mediator of Resolution of Inflammation and Injury
}

\author{
John L. Wallace,, ${ }^{1,2}$ Jose G.P. Ferraz, ${ }^{2}$ and Marcelo N. Muscara ${ }^{2,3}$
}

\begin{abstract}
Significance: Hydrogen sulfide is emerging as an important mediator of many aspects of inflammation, and perhaps most importantly as a factor promoting the resolution of inflammation and repair of injury. Recent Advances: In the gastrointestinal tract, $\mathrm{H}_{2} \mathrm{~S}$ has been shown to promote healing of ulcers and the resolution of mucosal inflammation. On the other hand, suppression of endogenous $\mathrm{H}_{2} \mathrm{~S}$ synthesis impairs mucosal defense and leads to increased granulocyte infiltration. $\mathrm{H}_{2} \mathrm{~S}$ has been exploited in the design of more effective and safe anti-inflammatory drugs. Critical Issues: Enteric bacteria can be a significant source of $\mathrm{H}_{2} \mathrm{~S}$, which could affect mucosal integrity; indeed, luminal $\mathrm{H}_{2} \mathrm{~S}$ can serve as an alternative to oxygen as a metabolic substrate for mitochondrial respiration in epithelial cells. Enterocytes and colonocytes thereby represent a "metabolic barrier" to the diffusion of bacteria-derived $\mathrm{H}_{2} \mathrm{~S}$ into the subepithelial space. A compromise of this barrier could result in modulation of mucosal function and integrity by bacterial $\mathrm{H}_{2} \mathrm{~S}$. Future Directions: Improvements in methods for measurement of $\mathrm{H}_{2} \mathrm{~S}$ and development of more selective inhibitors are crucial for gaining a better understanding of the pathophysiological importance of this mediator. Results from animal studies suggest that $\mathrm{H}_{2} \mathrm{~S}$-releasing agents are promising therapeutic agents for many indications, but these compounds need to be assessed in a clinical setting. Antioxid. Redox Signal. 17, 58-67.
\end{abstract}

\section{Introduction}

$\mathbf{W}$ HILE CLINICAL BENEFITS of hydrogen sulfide, at least in the context of sulfur hot springs, have been espoused for centuries, it is only in the past 20 years that $\mathrm{H}_{2} \mathrm{~S}$ has been recognized as an important mediator of physiological processes $(1,74)$. Indeed, as was the case for two other gaseous mediators (nitric oxide and carbon monoxide), the physiological effects of $\mathrm{H}_{2} \mathrm{~S}$ were overshadowed by the toxicity associated with high concentrations of this substance (44). There are many similarities among $\mathrm{H}_{2} \mathrm{~S}$, carbon monoxide, and nitric oxide. Enzymes for the synthesis of all three of these gaseous mediators have been identified and more continue to be identified, at least in the case of $\mathrm{H}_{2} \mathrm{~S}$ (50). All three mediators have very short half-lives in vivo and produce primarily beneficial effects at physiological concentrations while contributing to injury at super-physiological concentrations. All three of these mediators bind to hemoglobin $(48,63)$ and can influence activity and/or expression of enzymes responsible for synthesis of the other gaseous mediators (24, 39, 73-75). Also, attempts have been made to exploit the beneficial effects of each of the three gaseous mediators in designing novel therapeutic agents.
In this article, the ability of $\mathrm{H}_{2} \mathrm{~S}$ to modulate inflammation is reviewed, with a particular focus on the role of the mediator in resolution of inflammation. The use of $\mathrm{H}_{2} \mathrm{~S}$ as a therapeutic modality is also reviewed, along with the potential effects of bacteria-derived $\mathrm{H}_{2} \mathrm{~S}$ in modulating inflammation and mucosal integrity in the digestive tract and possibly in other organs.

\section{$\mathrm{H}_{2} \mathrm{~S}$ and Inflammation}

One of the first physiological effects of $\mathrm{H}_{2} \mathrm{~S}$ that was identified was its ability to relax vascular smooth muscle $(73,75)$, resulting in vasodilation, a hallmark of inflammation. Several studies have subsequently highlighted the importance of $\mathrm{H}_{2} \mathrm{~S}$ in inflammation $(27,30,54,56)$. As was the case for nitric oxide, the literature on $\mathrm{H}_{2} \mathrm{~S}$ in inflammation was initially contradictory, but in recent years a general pattern has emerged consistent with this mediator exerting anti-inflammatory effects, except at high concentrations (56). Moreover, there are now substantial data supportive of a role of $\mathrm{H}_{2} \mathrm{~S}$ in promoting resolution of inflammation and healing of injured tissue. Figure 1 summarizes some of the key effects of $\mathrm{H}_{2} \mathrm{~S}$ with respect to inflammation and injury. These

\footnotetext{
${ }^{1}$ Farncombe Family Digestive Health Research Institute, McMaster University, Hamilton, Ontario, Canada.

${ }^{2}$ Division of Gastroenterology, University of Calgary, Calgary, Alberta, Canada.

${ }^{3}$ Department of Pharmacology, University of Sao Paulo, Sao Paulo, Brazil.
} 
FIG. 1. Anti-inflammatory effects of $\mathrm{H}_{2} \mathrm{~S}$. This figure illustrates some of the key ways in which $\mathrm{H}_{2} \mathrm{~S}$ can reduce inflammation. $\mathrm{H}_{2} \mathrm{~S}$ suppresses leukocyte adherence to the vascular endothelium and migration of leukocytes into the subendothelial space, as well as reducing plasma exudation. $\mathrm{H}_{2} \mathrm{~S}$ has been shown to reduce expression of many pro-inflammatory cytokines, chemokines, and enzymes, most likely related to its ability to suppress activation of nuclear transcription factor- $\kappa \mathrm{B}(\mathrm{NF}-\kappa \mathrm{B}) . \mathrm{H}_{2} \mathrm{~S}$ is also a potent anti-oxidant and can induce apoptosis in neutrophils (which can lead to their phagocytosis by macrophages). Promotion of tissue repair by $\mathrm{H}_{2} \mathrm{~S}$ is likely mediated in part by its vasodilatory actions and en-

hancement of cyclooxygenase-2 (COX-2) expression and through promotion of angiogenesis. Inhibition of phosphodiesterases (PDE) by $\mathrm{H}_{2} \mathrm{~S}$ leads to elevated cyclic AMP and/or cyclic GMP levels, which can contribute to its antiinflammatory effects. $\mathrm{H}_{2} \mathrm{~S}$ exhibits anti-nociceptive effects in the viscera, likely due, at least in part, to activation of ATPsensitive potassium channels. In many cells in the body, and in particular in gastrointestinal epithelial cells, $\mathrm{H}_{2} \mathrm{~S}$ can act as an energy source (generating ATP), substituting for oxygen in mitochondrial respiration. This appears to contribute significantly to protection and repair of tissue injury.

effects include the ability of $\mathrm{H}_{2} \mathrm{~S}$ to inhibit leukocyte adherence to the vascular endothelium and the subsequent extravasation of leukocytes (72). The impact of this effect of $\mathrm{H}_{2} \mathrm{~S}$ can be seen in various models of inflammation, in which sulfide salts or $\mathrm{H}_{2} \mathrm{~S}$ donors are able to reduce infiltration of neutrophils and lymphocytes $(17,72)$. These effects are likely due, at least in part, to reduced expression of endothelial and/ or leukocyte adhesion molecule expression following exposure to $\mathrm{H}_{2} \mathrm{~S}$ (18). $\mathrm{H}_{2} \mathrm{~S}$ acts as a tonic down-regulator of leukocyte adherence; thus, inhibition of $\mathrm{H}_{2} \mathrm{~S}$ synthesis leads to leukocyte adherence (72). Treatment of rats with inhibitors of $\mathrm{H}_{2} \mathrm{~S}$ synthesis resulted in a marked increase in mucosal inflammation (elevated granulocyte levels) and an increase in susceptibility to injury $(18,58,59)$ in the gastrointestinal tract. This may have been in part due to reduced basal levels of cyclooxygenase-2 (COX-2) expression and a parallel reduction of mucosal prostaglandin $\mathrm{E}_{2}\left(\mathrm{PGE}_{2}\right)$ synthesis (61). COX-2 and $\mathrm{PGE}_{2}$ play important roles in the maintenance of mucosal defense in the digestive tract, as well as in modulating mucosal inflammation $(3,49,61,70,71)$.

In addition to modulating leukocyte adhesion and recruitment, $\mathrm{H}_{2} \mathrm{~S}$ can reduce plasma exudation (edema formation), while inhibitors of $\mathrm{H}_{2} \mathrm{~S}$ augment edema formation triggered by an inflammatory agent (59). These effects may contribute to the enhanced edema-reducing effects of $\mathrm{H}_{2} \mathrm{~S}$ releasing nonsteroidal anti-inflammatory drugs (NSAIDs) in rat models of acute (carrageenan) and chronic (Freund's adjuvant) paw swelling $(58,59)$.

The ability of $\mathrm{H}_{2} \mathrm{~S}$ to reduce inflammation has been demonstrated in a variety of animal models, including kaolin/ carrageenan-induced monoarthritis in rats (2), tobacco-smoke induced lung inflammation in mice $(12,23)$, synovitis in rats (17), ischemia-reperfusion injury in mice (76), and in rat and mouse models of colitis $(19,56,61)$. Whiteman et al. (66) demonstrated that $\mathrm{H}_{2} \mathrm{~S}$ is present in synovial fluid of patients with rheumatoid arthritis and osteoarthritis, with levels correlating to disease activity, but the role of $\mathrm{H}_{2} \mathrm{~S}$ in those conditions remains unclear.

$\mathrm{H}_{2} \mathrm{~S}$ was recently shown to inhibit phosphodiesterase activity, and this may contribute to anti-inflammatory actions in some circumstances (via elevation of intracellular cyclic AMP and/or cyclic GMP) (9). Scavenging of oxidants and peroxynitrite may also contribute to the anti-inflammatory activity of $\mathrm{H}_{2} \mathrm{~S}(64,65)$. Inhibition of nuclear transcription factor- $\kappa \mathrm{B}$ (NF$\kappa \mathrm{B})$ has been reported in several models $(27,28,38)$, and consistent with this, $\mathrm{H}_{2} \mathrm{~S}$ reduces pro-inflammatory cytokine, chemokine, and enzyme (e.g., inducible nitric oxide synthase [iNOS]) expression $(17,19,51,67)$. In addition, the antioxidant activity of $\mathrm{H}_{2} \mathrm{~S}$ can be mediated by up-regulation of enzymes such as superoxide dismutase, glutathione peroxase dismutase, and thioredoxin as assessed in rats subjected to intestinal ischemia-reperfusion injury (31) or in brain endothelial cells under methionine-induced oxidative stress in vitro (53) or even by inhibition of NADPH oxidase activity, as in the case of osteoblasts exposed to hydrogen peroxide in vitro (69). With many of these putative mechanisms of action of $\mathrm{H}_{2} \mathrm{~S}$, it is unclear if the concentrations required for such actions are achieved in a physiological setting. Difficulties in measuring $\mathrm{H}_{2} \mathrm{~S}$ levels in vivo further complicate the assessment of the relative significance of these mechanisms in various scenarios. 
$\mathrm{H}_{2} \mathrm{~S}$ has been shown to exert anti-nociceptive effects in some $(15,18,19,62)$, but not all (37) visceral pain studies. The discrepancies may be related to the different methods for measuring pain or to different doses or routes of administration of the $\mathrm{H}_{2} \mathrm{~S}$-releasing agents. In a recent study performed in our laboratory, we found that two $\mathrm{H}_{2} \mathrm{~S}$ generating substances (NaHS and Lawesson's reagent) dose-dependently reduced gastric distention-induced visceral pain (measured through cardio-autonomic responses) in the rat in an ATP-sensitive potassium channel-dependent manner (62). The ability of $\mathrm{H}_{2} \mathrm{~S}$ to exert peripheral antinociceptive effects has also been demonstrated in some, but not all studies. While anti-nociceptive effects of $\mathrm{H}_{2} \mathrm{~S}$ were reported by Cunha et al. (13) in a model of peripheral pain induced by bacterial endotoxin and by Ekundi-Valentim et al. (17) in rats with carrageenan-induced knee joint synovitis (see Fig. 2), Andruski et al. (2) observed a significant inhibition of leukocyte recruitment by an $\mathrm{H}_{2} \mathrm{~S}$ donor in a rat model of monoarthritis, but no significant effect on pain sensitivity.
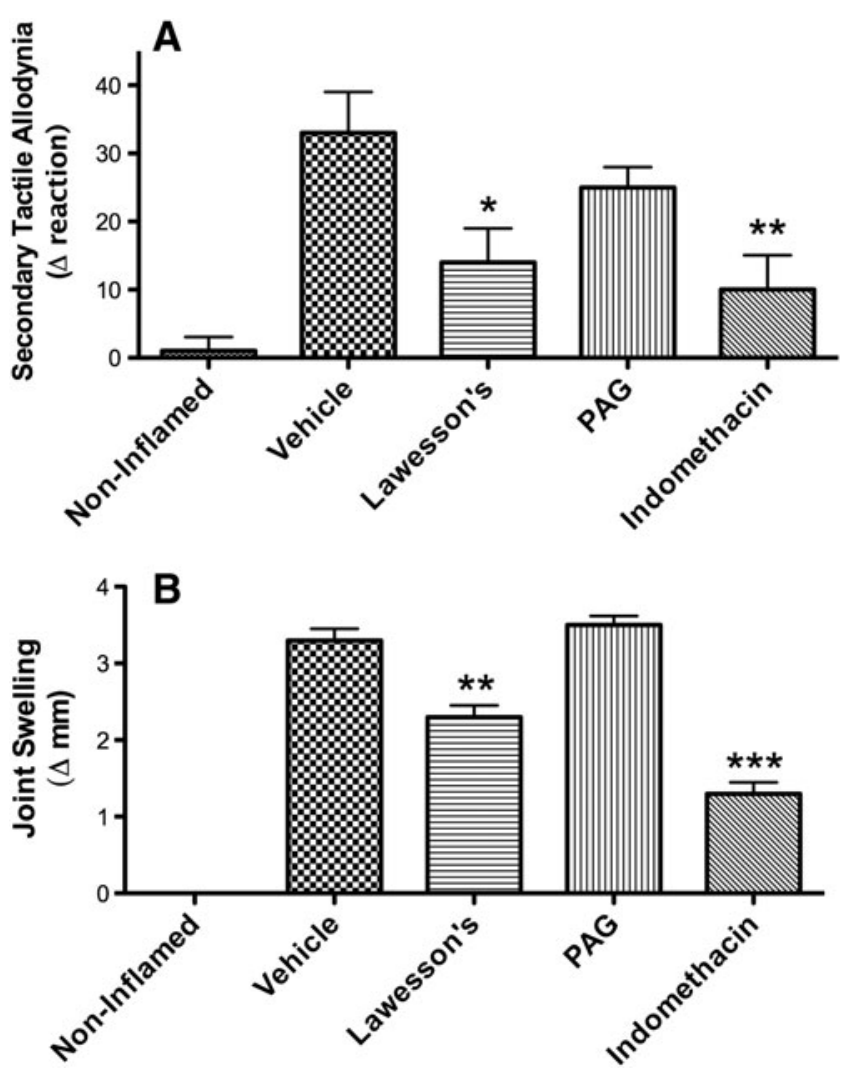

FIG. 2. Anti-nociceptive and anti-inflammatory effects of hydrogen sulfide in experimental (carrageenan-induced) synovitis in rats. (A) Pain responses and (B) joint swelling. Pretreatment with an $\mathrm{H}_{2} \mathrm{~S}$ donor (Lawesson's reagent; $3.6 \mu \mathrm{mol}$ intra-articularly), markedly reduced secondary tactile allodynia, while an inhibitor of $\mathrm{H}_{2} \mathrm{~S}$ synthesis (D/Lpropargylglycine [PAG], $53 \mu \mathrm{mol}$ intra-articularly) had no significant effect. Indomethacin $(6 \mathrm{mg} / \mathrm{kg}$ intraperitoneally) was used as a positive control. ${ }^{*} p<0.05,{ }^{* *} p<0.01,{ }^{* * *} p<0.001$ versus the vehicle-treated group. Adapted from previously published data (17).

\section{$\mathrm{H}_{2} \mathrm{~S}$ and Resolution of Inflammation/Injury}

With the ability to inhibit so many elements of acute inflammation, it is not surprising that $\mathrm{H}_{2} \mathrm{~S}$ contributes significantly to the resolution of inflammation and injury. Inflammatory reactions are driven largely by soluble, proinflammatory mediators, such as leukotrienes, histamine, bradykinin, platelet-activating factor, and interleukin (IL)-1, to name just a few (49). Counteracting the effects of these pro-inflammatory mediators are a variety of soluble mediators that down-regulate inflammation, including lipoxins, certain prostaglandins, annexin-1 (AnxA-1), and IL-10 (49). An over-production of pro-inflammatory mediators or an under-production of anti-inflammatory mediators can lead to progression from acute to chronic inflammation. Resolution of inflammation occurs through removal of the triggers of the inflammatory response (e.g., a foreign body or organism), inhibition of the recruitment of neutrophils to the site of injury, and induction of apoptosis of the infiltrated neutrophils and their subsequent clearance by macrophages (Fig. 3). Macrophages undergo a phenotype shift from pro-inflammatory to anti-inflammatory during this process.

There is emerging evidence that $\mathrm{H}_{2} \mathrm{~S}$ may participate in several stages of the process of resolution of inflammation. As already mentioned, $\mathrm{H}_{2} \mathrm{~S}$ can reduce leukocyte adherence to the vascular endothelium and leukocyte migration to sites of injury (72). $\mathrm{H}_{2} \mathrm{~S}$ can also induce neutrophil apoptosis (34), and there is recent evidence that it can trigger significant changes in macrophage function consistent with a shift to a pro-resolution phenotype (16). Specifically, exposure of murine bone marrow-derived macrophages to $\mathrm{H}_{2} \mathrm{~S}$ resulted in a significant enhancement of phagocytosis of bacteria. $\mathrm{H}_{2} \mathrm{~S}$ also suppressed endotoxin-induced tumor necrosis factor $\alpha$ $(\mathrm{TNF} \alpha)$ production by macrophages, while enhancing chemotaxis. In vivo, in a mouse peritonitis model, $\mathrm{H}_{2} \mathrm{~S}$ significantly reduced granulocyte infiltration while maintaining macrophage numbers (16).

$\mathrm{H}_{2} \mathrm{~S}$ also appears to interact with other pro-resolution mediators. $\mathrm{H}_{2} \mathrm{~S}$ modulates COX-2 expression in the gastrointestinal tract, which plays a crucial role in resolution of inflammation and injury $(3,49,56,61,70,71)$. Recently reported work from Brancaleone et al. (8) demonstrates an important interaction between $\mathrm{H}_{2} \mathrm{~S}$ and AnxA-1. AnxA-1 is a well-characterized anti-inflammatory and pro-resolution mediator that has also been shown to contribute to gastrointestinal integrity and repair $(36,41)$. Brancaleone et al. (8) observed that an $\mathrm{H}_{2} \mathrm{~S}$ donor (NaHS, 10-100 $\mu \mathrm{M}$ ) elicited intense mobilization of AnxA-1 from the cytosol to the membrane of human neutrophils. It also markedly suppressed IL-1-induced leukocyte adhesion and emigration in mesenteric venules of wild type, but not AnxA1-deficient mice. There were also effects of endogenous AnxA1 on $\mathrm{H}_{2} \mathrm{~S}$ synthesis. Thus, mice deficient of AnxA1 displayed marked up-regulation of cystathionine $\beta$ synthase (CBS) and cystathionine $\gamma$-lyase (CSE) in a variety of tissues as compared with wild-type mice. Moreover, $\mathrm{H}_{2} \mathrm{~S}$ could down-regulate other inflammatory pathways in macrophages from wild-type mice (i.e., significant suppression of iNOS and COX-2 expression in lipopolysaccharide-stimulated bone marrow-derived macrophages) but not in macrophages obtained from AnxA1-deficient mice. The authors concluded that these data demonstrate interlinks between the $\mathrm{H}_{2} \mathrm{~S}$ and AnxA1 
FIG. 3. Resolution of inflammation. Inflammatory reactions to injury or infection are largely coordinated by soluble mediators (pro-inflammatory and antiinflammatory). In the early stages of an inflammatory reaction, the proinflammatory mediators predominate, resulting in the recruitment of inflammatory cells (such as neutrophils) and platelets to the site of injury/infection. Monocyte recruitment follows, with the subsequent transformation to macrophages, which are crucial for tissue repair. In part driven by anti-inflammatory mediators such as $\mathrm{H}_{2} \mathrm{~S}$, the infiltrated neutrophils begin to undergo apoptosis, which causes macrophages to shift their phenotype from pro-inflammatory to anti-inflammatory. Engulfment of apoptotic neutrophils (polymorphonuclear leukocytes [PMN]) by macrophages is a key event in resolution of inflammation.

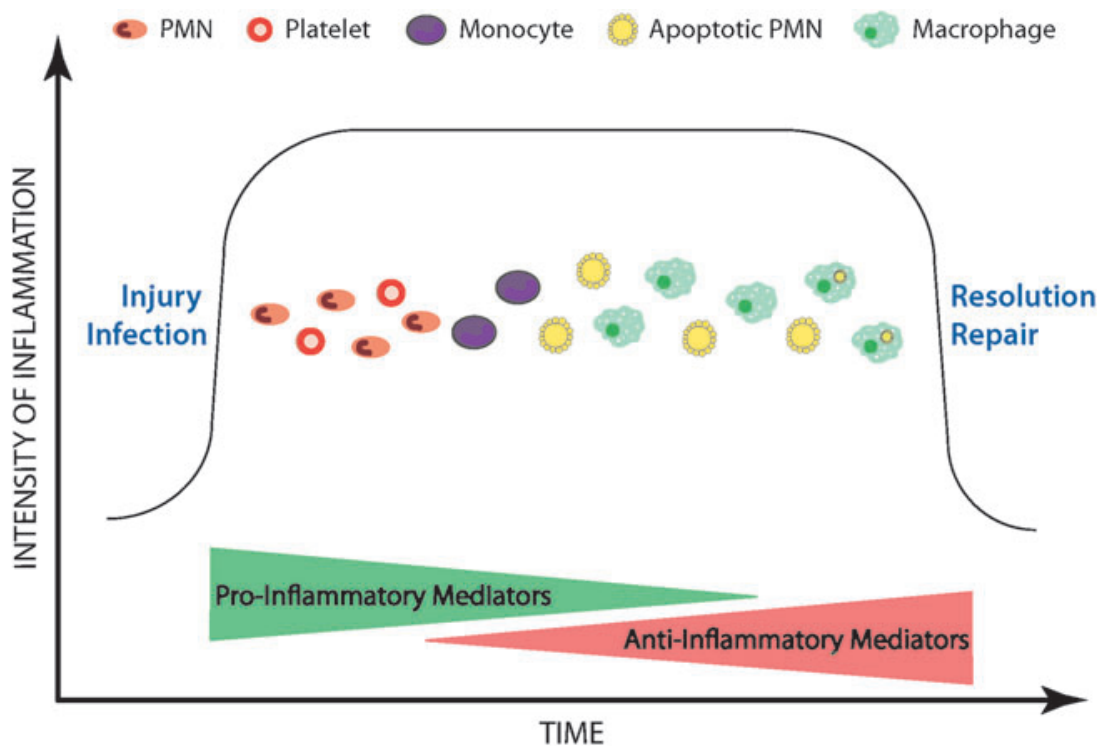

rats that survived a week-long treatment with an inhibitor of $\mathrm{H}_{2} \mathrm{~S}$ synthesis, the colonic damage was significantly worse than that observed in vehicle-treated controls. Interestingly, there was a marked thickening of the smooth muscle in the colon in the rats treated with an inhibitor of $\mathrm{H}_{2} \mathrm{~S}$ synthesis (61).

Additional evidence that $\mathrm{H}_{2} \mathrm{~S}$ could promote resolution of colitis came from studies in which $\mathrm{H}_{2} \mathrm{~S}$ donors were administered to rats or mice with colitis $(19,61,68)$. Irrespective of the $\mathrm{H}_{2} \mathrm{~S}$ donor used, a significant reduction of the severity of colitis was observed, with a marked inhibition of granulocyte infiltration into the colonic tissue $(19,61)$. The latter observation is important, since much of the tissue injury associated with colitis is likely produced by infiltrating granulocytes. In these studies, the $\mathrm{H}_{2} \mathrm{~S}$-generating agents significantly reduced colonic expression of $\mathrm{TNF} \alpha$ (protein and mRNA); in other studies, they also reduced expression of interferon- $\gamma$, IL- $1 \beta$, and iNOS $(19,61,68)$. Consistent with these findings, allyl trisulfide, a garlic-derived substance that release $\mathrm{H}_{2} \mathrm{~S}$ (7), was shown to suppress TNF $\alpha$ expression and NF- $\kappa \mathrm{B}$ activation in colonic biopsies from patients with ulcerative colitis (6).

\section{$\mathrm{H}_{2} \mathrm{~S}$ in Novel Therapeutics}

The ability of $\mathrm{H}_{2} \mathrm{~S}$ to enhance gastrointestinal resistance to injury, to promote repair of damaged tissue, and to reduce mucosal inflammation make it an attractive substance to exploit in designing novel drugs for treatment of gastrointestinal injury and inflammation $(10,54)$. We have synthesized and characterized the effects of an $\mathrm{H}_{2} \mathrm{~S}$-releasing derivative of mesalamine in animal models of colitis (mesalamine is the first-line therapy for colitis) and have observed a significant enhancement of anti-inflammatory activity as compared to the parent drug $(19,56) . \mathrm{H}_{2} \mathrm{~S}$-releasing derivatives of several NSAIDs have been assessed in animal models, with the consistent finding of greatly reduced gastrointestinal toxicity and, in some cases, enhanced anti-inflammatory activity $(30,54,58$, 59). An $\mathrm{H}_{2} \mathrm{~S}$-releasing derivative of naproxen has been particularly well characterized. The anti-inflammatory activity of the compound, called ATB-346, is comparable to that of the parent drug (58). However, even at exceptionally high doses the inflammation, with perforation of the bowel wall and death occurring in most animals within a few days (61). In the 


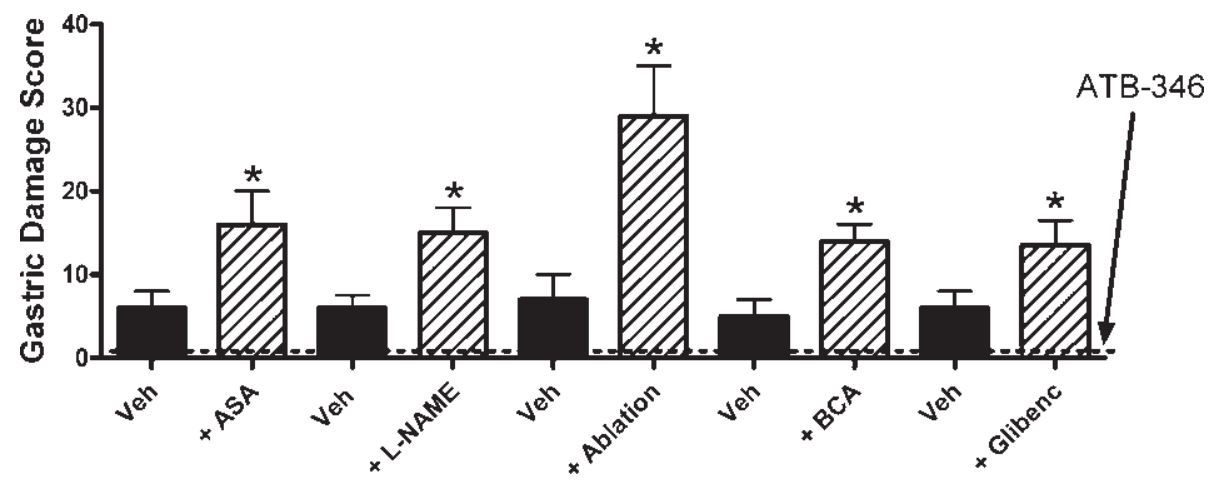
treatment with an inhibitor of cystathionine $\beta$-synthase ( $\beta$-cyanoalanine [BCA], $50 \mathrm{mg} / \mathrm{kg}$ ) or an antagonist of ATP-sensitive $\mathrm{K}^{+}$channels (glibenclamide; $10 \mathrm{mg} / \mathrm{kg}$ ) each significantly increased the severity of naproxen-induced gastric damage $\left({ }^{*} p<0.05\right.$ vs. corresponding vehicle-treated group). However, ATB-346 did not produce significant gastric damage in any of the rats receiving these treatments (dotted line). Adapted from previously published data (55).

(100 times the human dose on a per kilogram basis), ATB-346 caused negligible gastric damage in healthy rats. While impressive, studies performed in healthy rodents may not serve as a good predictor of how an anti-inflammatory drug will behave in humans with diseases such as osteoarthritis and rheumatoid arthritis alongside other co-morbidities for gastrointestinal damage. To more rigorously assess the gastric safety of ATB-346, studies were performed in rats in which gastric mucosal defense was significantly compromised (58). This was achieved by interfering with the production of mediators known to contribute to mucosal defense (e.g., nitric oxide, hydrogen sulfide), co-administering another drug that can damage the stomach (e.g., low-dose aspirin, frequently co-administered with NSAIDs in a clinical setting), blocking receptors believed to contribute to mucosal defense (e.g., glibenclamide to block ATP-sensitive $\mathrm{K}^{+}$channels), or ablating sensory afferent nerves (via neonatal administration of capsaicin), which play a crucial role in mucosal responses to luminal irritants (55). As illustrated in Fig. 4, naproxen produced a low level of damage in control rats at the dose tested $(60 \mu \mathrm{mol} / \mathrm{kg})$. However, with each approach to compromising mucosal defense, the extent of injury induced by naproxen was significantly increased (two- to sixfold). In contrast, ATB346 at an equimolar dose did not produce significant damage in controls or in mucosal defense-compromised animals. Particularly interesting is the observation that ATB-346 was still gastric safe in rats pretreated with glibenclamide. Many actions of $\mathrm{H}_{2} \mathrm{~S}$ have been attributed to activation of ATPsensitive $\mathrm{K}^{+}$channels $(14,62,74)$. This observation suggests that the mechanism underlying the gastric tolerability of ATB346 is unrelated to activation of ATP-sensitive $\mathrm{K}^{+}$channels. It is also noteworthy that ATB-346 suppressed gastric prostaglandin synthesis as effectively as equimolar doses of naproxen (58). Thus, the compound can compensate for the reduced mucosal resistance to injury that occurs when prostaglandin synthesis is markedly reduced (presumably because $\mathrm{H}_{2} \mathrm{~S}$ can exert many of the same effects, in terms of mucosal defense, as prostaglandins do).

Another major clinical concern with respect to the use of NSAIDs is their ability to interfere with the healing of ulcers (55). This effect is likely related to suppression of COX-2 activity by the NSAIDs. COX-2-derived prostaglandin synthesis by cells at the ulcer margin is critically important for re- epithelialization and angiogenesis (55). As shown in Fig. 5, naproxen and celecoxib (nonselective COX inhibitor and selective COX-2 inhibitor, respectively) each significantly impaired the healing of gastric ulcers in mice when administered twice daily over a 4-day period. In sharp contrast, the $\mathrm{H}_{2} \mathrm{~S}$ releasing derivative of naproxen (ATB-346) significantly accelerated the healing of pre-existing gastric ulcers (58). This is consistent with previous reports that L-cysteine and $\mathrm{H}_{2} \mathrm{~S}$ generating agents could accelerate experimental ulcer healing, while inhibitors of $\mathrm{H}_{2} \mathrm{~S}$ synthesis impaired ulcer healing $(56,60)$. The beneficial effects of $\mathrm{H}_{2} \mathrm{~S}$ on ulcer healing may be attributable to the stimulatory effects of $\mathrm{H}_{2} \mathrm{~S}$ on angiogenesis (40).

From a clinical perspective, the main focus in terms of the gastrointestinal toxicity of NSAIDs is the stomach and

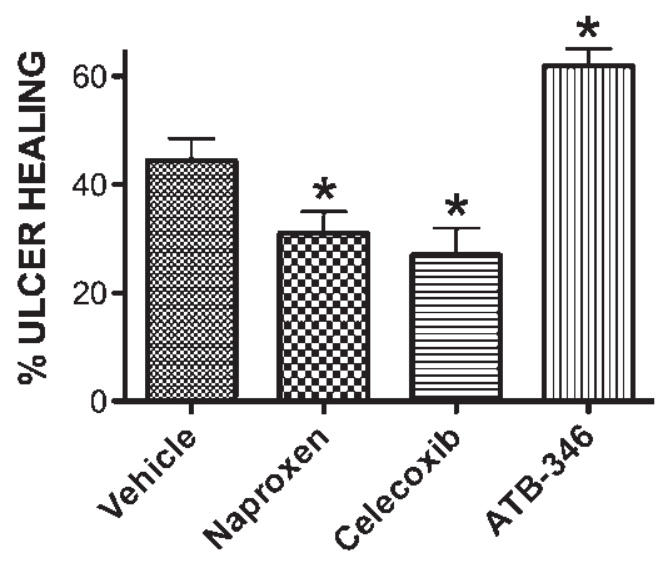

FIG. 5. Experimental gastric ulcer healing with ATB-346, an $\mathrm{H}_{2} \mathrm{~S}$-releasing derivative of naproxen. The extent of healing of gastric ulcers in mice treated twice daily over a 4day period with one of three NSAIDs or vehicle was examined. Gastric ulcers were induced by brief serosal application of acetic acid (55). Beginning 3 days later, the mice began treatment with naproxen, ATB-346 (each at $60 \mu \mathrm{mol} / \mathrm{kg}$ ), celecoxib (at $30 \mu \mathrm{mol} / \mathrm{kg}$ ), or vehicle. The ulcer area at the end of the treatment period was compared to that in mice euthanized 3 days after ulcer induction (no drug treatment), and the "percent ulcer healing" was calculated. * $p<0.05$ versus the vehicle-treated group ( $n \geq 5$ per group). Adapted from previously published data (55). 
proximal duodenum. This is largely due to the relative ease of endoscopically viewing these regions. However, it is becoming increasingly clear that NSAIDs frequently produce significant injury in the small intestine. Indeed, the jejunum and ileum may be the major sites of NSAID-induced bleeding (55, 57). Damage to these regions induced by NSAIDs is determined by a number of factors, but most important is the enterohepatic circulation of the NSAIDs, leading to repeated exposure of the epithelium to the NSAIDs and bile, and also to marked changes in the numbers and type of bacteria in the small intestine (57). The $\mathrm{H}_{2} \mathrm{~S}$-releasing derivative of naproxen (ATB-346), when given twice daily to rats for 5 days, did not produce detectable small intestinal damage (58). This was in marked contrast to the parent drug, naproxen, which elicited widespread ulceration and bleeding in the small intestine.

\section{Bacteria-Derived $\mathrm{H}_{2} \mathrm{~S}$ : A Modulator of Inflammation or Mucosal Function?}

Many of the species of bacteria residing in the human gastrointestinal tract are capable of producing $\mathrm{H}_{2} \mathrm{~S}$. Some early studies suggested that the concentrations of $\mathrm{H}_{2} \mathrm{~S}$ in the lumen of the gut were extremely high relative to levels that occur in the body $(32,33)$. Largely based on these data, and observations of adverse effects of such concentrations of $\mathrm{H}_{2} \mathrm{~S}$ on colonocyte function (5), roles for $\mathrm{H}_{2} \mathrm{~S}$ in the pathogenesis of inflammatory bowel disease and colon cancer were suggested $(4,45,46)$. However, this hypothesis has been challenged (25, $26,38,42)$, as has the notion that there are millimolar concentrations of free $\mathrm{H}_{2} \mathrm{~S}$ in the lumen of the gut $(27,28,38,42$, 43). Most of the $\mathrm{H}_{2} \mathrm{~S}$ that is produced in the lumen of the intestine is bound to fecal material and therefore not available to diffuse through the epithelium. The $\mathrm{H}_{2} \mathrm{~S}$ that is available, likely in micromolar concentrations, is absorbed and rapidly metabolized (51). Indeed, efficient detoxification occurs via a number of enzymes present in the mucosa, and no impairment of these detoxification systems has been detected in patients with ulcerative colitis or Crohn's disease (42). Based on studies utilizing a rat model of colitis (dextran sodium sulfate), Furne et al. (21) concluded that "excessive $\mathrm{H}_{2} \mathrm{~S}$ production" did not contribute to tissue injury.

Even before reaching the mucosa, however, there is substantial metabolism of $\mathrm{H}_{2} \mathrm{~S}$ in the mitochondria of enterocytes and colonocytes. Virtually all $\mathrm{H}_{2} \mathrm{~S}$ that crosses the apical membrane of enterocytes and colonocytes is rapidly oxidized to thiosulfate $(22,28)$. This is accomplished mainly by a mitochondrial enzyme, sulfide quinone reductase, which rapidly consumes $\mathrm{H}_{2} \mathrm{~S}$, thereby providing energy to the cell and keeping $\mathrm{H}_{2} \mathrm{~S}$ concentrations at nontoxic levels (26) (Fig. 6). This ancestral capacity, predating photosynthesis, is common to organisms living in low-light, low-oxygen conditions (52). As mentioned above, efficient detoxification also occurs via a number of mucosal enzymes (52). The epithelium could therefore be viewed not only as a physical barrier, protecting organisms from potentially harmful substances in the lumen of the digestive tract, but also a metabolic barrier providing additional protection. When there is an intact, healthy epithelium, luminally produced $\mathrm{H}_{2} \mathrm{~S}$ likely has little, if any, effect on mucosal function. However, in cases in which the epithelium is dysfunctional or damaged, it remains possible that $\mathrm{H}_{2} \mathrm{~S}$ produced by bacteria could exert significant effects on several aspects of mucosal function, including secretion (via

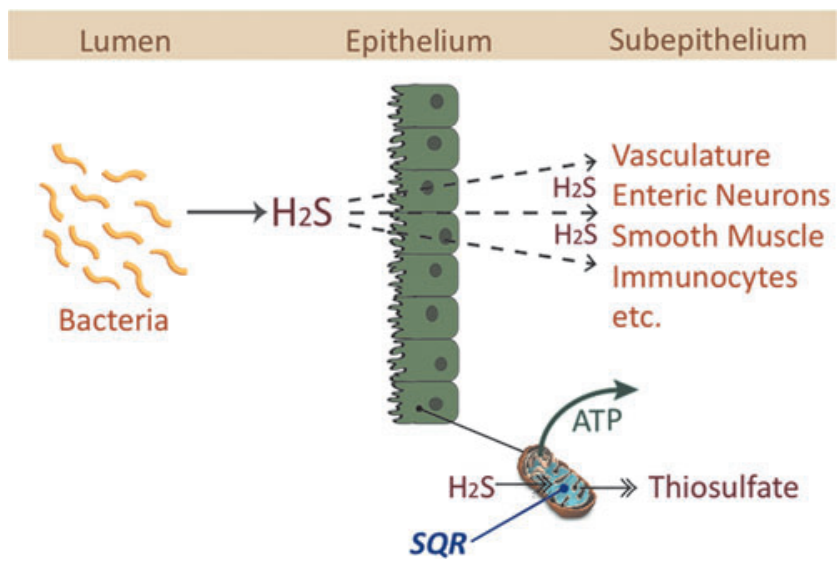

FIG. 6. The colonic epithelium as a metabolic barrier to bacteria-derived $\mathrm{H}_{2} \mathrm{~S}$. Many species of bacteria can produce $\mathrm{H}_{2} \mathrm{~S}$ but most is bound to fecal material. The small amount that is free to diffuse across the epithelium is rapidly metabolized, primarily via mitochondrial sulfide quinone reductase (SQR) to thiosulfate, generating adenosine triphosphate (ATP) in the process. Thus, $\mathrm{H}_{2} \mathrm{~S}$ is an important energy source for colonocytes. When the epithelium is damaged or dysfunctional, more $\mathrm{H}_{2} \mathrm{~S}$ may escape metabolism and reach the subepithelial space, where it can affect many functions, including epithelial secretion, blood flow, smooth muscle contractility, and mucosal defense.

effects on enteric neurons) (47), pain sensation (14), blood flow $(18,63)$, and smooth muscle contractility $(29,63)$. Indeed, an impaired colonic "barrier" to diffusion of $\mathrm{H}_{2} \mathrm{~S}$ from the lumen may explain in part the marked beneficial effects of $\mathrm{H}_{2} \mathrm{~S}$ donors, when administered by enema, in models of colitis $(19,61)$.

As already reviewed, colonic production of $\mathrm{H}_{2} \mathrm{~S}$ is markedly increased when the mucosa is inflamed $(20,61)$. Because measurements of $\mathrm{H}_{2} \mathrm{~S}$ in this context are generally performed in vitro, and because of the capacity of some colonic bacteria to produce $\mathrm{H}_{2} \mathrm{~S}$, we performed a series of studies to determine if some portion of what we measure as "colonic $\mathrm{H}_{2} \mathrm{~S}$ synthesis" is actually bacterial $\mathrm{H}_{2} \mathrm{~S}$ synthesis (20). These studies involved the use of germ-free mice and mice colonized with Altered Schaedler flora. There was no difference in colonic $\mathrm{H}_{2} \mathrm{~S}$ synthesis between these two groups of mice, indicating that any bacterial contribution (in the colonized mice) was negligible (Fig. 7). We also measured tissue and fecal $\mathrm{H}_{2} \mathrm{~S}$ production from healthy mice and mice with colitis induced by trinitrobenzene sulfonic acid. Colonic $\mathrm{H}_{2} \mathrm{~S}$ synthesis was markedly increased in parallel with the severity of colitis and the extent of granulocyte infiltration (Fig. 8), but neutrophils (the main infiltrating granulocytes) were not a significant source of $\mathrm{H}_{2} \mathrm{~S}$ synthesis. Taken together, these studies clearly demonstrated that the $\mathrm{H}_{2} \mathrm{~S}$ synthesis measured using the in vitro zinctrapping method was derived from the colonic tissue itself, rather than from any bacteria adherent to the tissue samples. On the other hand, certain bacteria may be able to modulate colonic $\mathrm{H}_{2} \mathrm{~S}$ synthesis. For example, butyrate, which is produced by Bifidobacteria and Faecalibacterium prausnitzii, has been shown to regulate $\mathrm{H}_{2} \mathrm{~S}$ production, at least in transformed colonocytes (WiDr cells) (11). Butyrate increased expression of CBS and CSE, the major enzymatic sources of $\mathrm{H}_{2} \mathrm{~S}$ in these cells. 


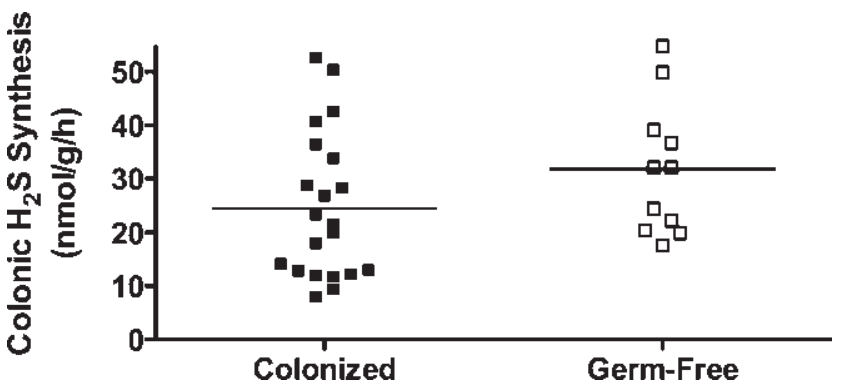

FIG. 7. Colonic hydrogen sulfide synthesis, as measured by the zinc acetate-trapping method, does not include significant "contamination" by bacterial $\mathrm{H}_{2} \mathrm{~S}$ synthesis. Mice that were colonized by Altered Schaedler Flora were compared with mice that were raised germ-free. There was considerable variation from mouse to mouse in terms of colonic $\mathrm{H}_{2} \mathrm{~S}$ synthesis, but there was no significant difference between the colonized and germ-free mice. Adapted from previously published data (20).

A
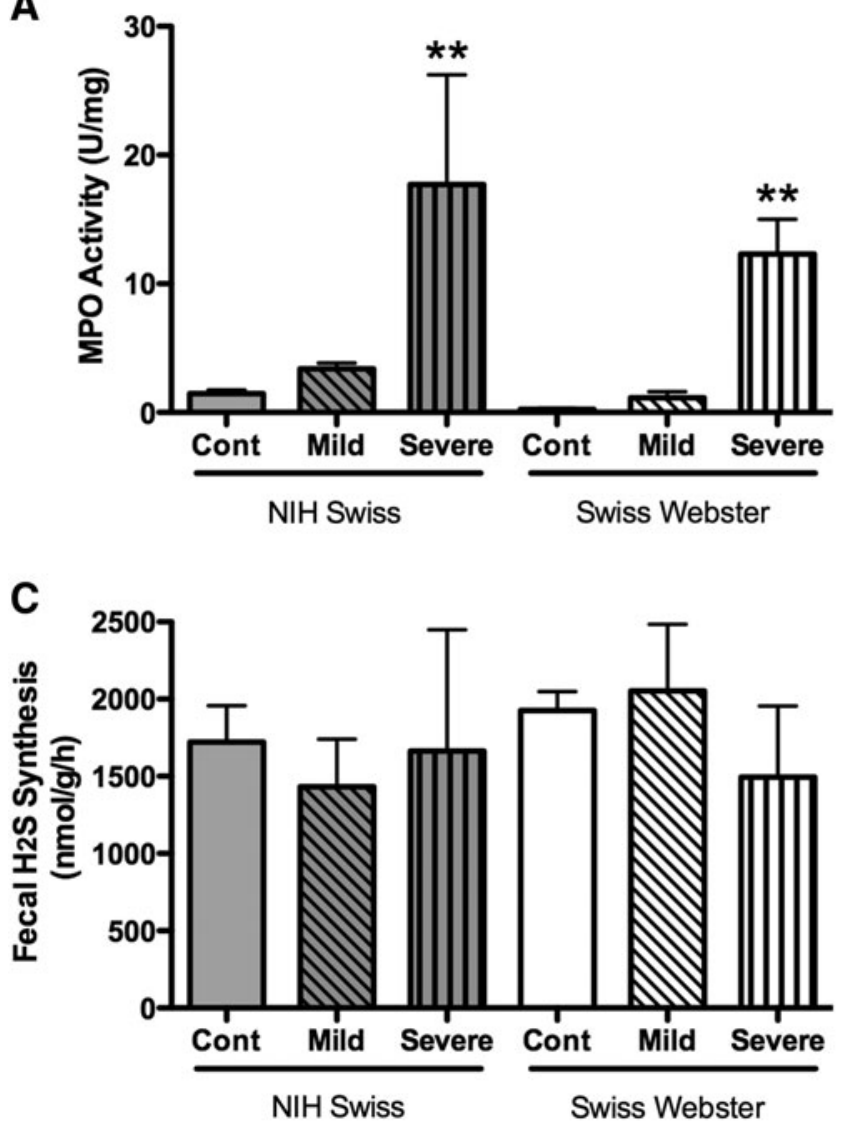

\section{Conclusions and Future Directions}

The contribution of $\mathrm{H}_{2} \mathrm{~S}$ as a modulator of inflammation is becoming more clear, but studies of this gaseous mediator continue to be limited by the lack of highly selective inhibitors of its synthesis and simple methods for measuring its production in vivo. Pathways of synthesis of $\mathrm{H}_{2} \mathrm{~S}$ other than via CSE and CBS are becoming evident and represent an important area for future research.

Novel therapeutic agents that release $\mathrm{H}_{2} \mathrm{~S}$ and exhibit significant anti-inflammatory and/or gastrointestinal mucosal protective effects look promising in preclinical studies. The mechanisms through which $\mathrm{H}_{2} \mathrm{~S}$ increases resistance to mucosal injury, promotes repair of injury, and accelerates resolution of inflammation remain incompletely understood. Evaluation of $\mathrm{H}_{2} \mathrm{~S}$-releasing drugs in a clinical setting will provide insight as to whether or not the exploitation of $\mathrm{H}_{2} \mathrm{~S}$ as a therapeutic agent will live up to the promise.

The ability of many enteric bacteria to produce $\mathrm{H}_{2} \mathrm{~S}$ and the possibility that bacterially derived $\mathrm{H}_{2} \mathrm{~S}$ could affect mucosal function are intriguing. The intestinal epithelium appears to
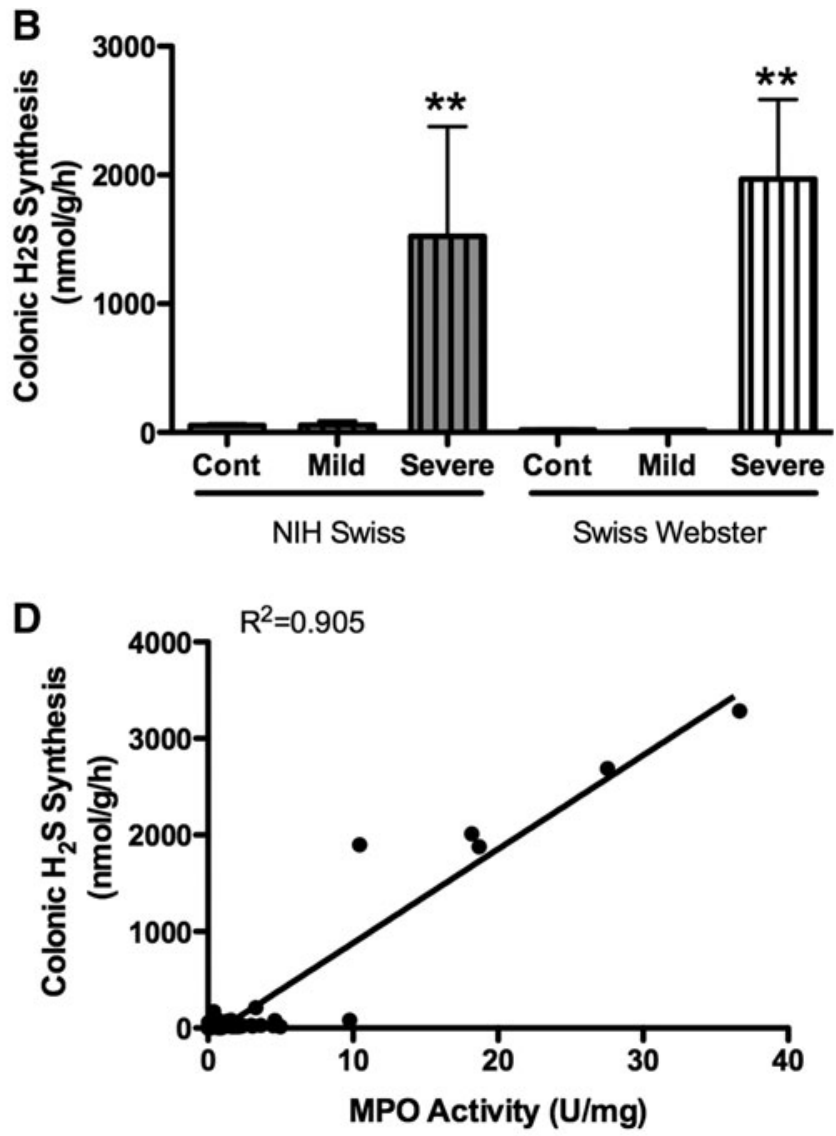

FIG. 8. Colonic hydrogen sulfide synthesis (as measured by the zinc acetate-trapping method) is markedly up-regulated during injury/inflammation, and there is negligible bacterial contribution. Colitis was induced via intrarectal administration of trinitrobenzene sulfonic acid (20). (A) Colonic myeloperoxidase (MPO) activity, a biochemical marker of granulocyte infiltration. In both strains of mice examined, MPO activity increased with the severity of the colitis. (B) Colonic $\mathrm{H}_{2} \mathrm{~S}$ synthesis, which similarly increased in parallel with the severity of colitis. (C) In contrast, fecal hydrogen sulfide synthesis did not differ between healthy mice and mice with mild or severe colitis, suggesting negligible contribution of bacteria to what was measured as "colonic" $\mathrm{H}_{2} \mathrm{~S}$. (D) There was a strong correlation between the extent of inflammation (MPO activity) and colonic $\mathrm{H}_{2} \mathrm{~S}$ synthesis. There was no such correlation between fecal $\mathrm{H}_{2} \mathrm{~S}$ synthesis and colonic MPO activity. ${ }^{* *} p<0.01$ versus the corresponding control (cont) group. Adapted from previously published data (20). 
act as a metabolic barrier to diffusion of significant concentrations of $\mathrm{H}_{2} \mathrm{~S}$ into the mucosa, at least when the epithelium is healthy. On the other hand, $\mathrm{H}_{2} \mathrm{~S}$ is an important metabolic fuel for enterocytes. Given the widespread actions that $\mathrm{H}_{2} \mathrm{~S}$ can exert on various cell types in the subepithelial compartment (e.g., blood vessels, enteric nerves, smooth muscle cells, resident and infiltrating immunocytes), it is important to determine the extent to which bacterial $\mathrm{H}_{2} \mathrm{~S}$ can "escape" epithelial and mucosal inactivation in certain circumstances and disease conditions.

\section{Acknowledgments}

This work is supported by grants from the Canadian Institutes of Health Research and the Crohn's and Colitis Foundation of Canada.

\section{Author Disclosure Statement}

Dr. Wallace holds shares in Antibe Therapeutics, a company developing $\mathrm{H}_{2} \mathrm{~S}$-releasing anti-inflammatory drugs. No conflicts of interest exist for the other authors.

\section{References}

1. Abe $\mathrm{K}$ and Kimura $\mathrm{H}$. The possible role of hydrogen sulfide as an endogenous neuromodulator. J Neurosci 16: 1066-1071, 1996.

2. Andruski B, McCafferty DM, Ignacy T, Millen B, and McDougall JJ. Leukocyte trafficking and pain behavioral responses to a hydrogen sulfide donor in acute monoarthritis. Am J Physiol Regul Integr Comp Physiol 295: R814-R820, 2008.

3. Asfaha S, MacNaughton WK, Appleyard CB, Chadee K, and Wallace JL. Persistent epithelial dysfunction and bacterial translocation after resolution of intestinal inflammation. Am J Physiol 281: G635-G644, 2001.

4. Attene-Ramos MS, Wagner ED, Plewa MJ, et al. Evidence that hydrogen sulfide is a genotoxic agent. Mol Cancer Res 4: 9-14, 2006.

5. Babidge W, Millard S, and Roediger W. Sulfides impair short chain fatty acid beta-oxidation at acyl-CoA dehydrogenase level in colonocytes: implications for ulcerative colitis. Mol Cell Biochem 181: 117-124, 1998.

6. Bai AP, Ouyang Q, and Hu RW. Diallyl trisulfide inhibits tumor necrosis factor-alpha expression in inflamed mucosa of ulcerative colitis. Dig Dis Sci 50: 1426-1431, 2005.

7. Benavides GA, Squadrito GL, Mills RW, et al. Hydrogen sulfide mediates the vasoactivity of garlic. Proc Natl Acad Sci USA 104: 17977-17982, 2007.

8. Brancaleone V, Sampaio A, Cirino C, Flower RJ, and Perretti M. A novel cross-talk in resolution: $\mathrm{H}_{2} \mathrm{~S}$ activates the annexin A1 pathway. Inflammation Res, in press.

9. Bucci M, Papapetropoulos A, Vellecco V, Zhou Z, Pyriochou A, Roussos C, Roviezzo F, Brancaleone V, and Cirino G. Hydrogen sulfide is an endogenous inhibitor of phosphodiesterase activity. Arterioscler Thromb Vasc Biol 30: 1998-2004, 2010.

10. Caliendo G, Cirino G, Santagada V, and Wallace JL. Synthesis and biological effects of hydrogen sulfide $\left(\mathrm{H}_{2} \mathrm{~S}\right)$ : development of $\mathrm{H}_{2} \mathrm{~S}$-releasing drugs as pharmaceuticals. J Med Chem 53: 6275-6286, 2010.

11. Cao Q, Zhang L, Yang G, Xu C, and Wang R. Butyratestimulated $\mathrm{H}_{2} \mathrm{~S}$ production in colon cancer cells. Antioxid Redox Signal 12: 1101-1109, 2010.

12. Chen $Y H$, Wang PP, Wang XM, He YJ, Yao WZ, Qi YF, and Tang CS. Involvement of endogenous hydrogen sulfide in cigarette smoke-induced changes in airway responsiveness and inflammation of rat lung. Cytokine 53: 334-341, 2011.

13. Cunha TM, Dal-Secco D, Verri WA Jr, Guerrero AT, Souza GR, Vieira SM, Lotufo CM, Neto AF, Ferreira SH, and Cunha FQ. Dual role of hydrogen sulfide in mechanical inflammatory hypernociception. Eur J Pharmacol 590: 127-135, 2008.

14. Distrutti E, Sediari L, Mencarelli A, et al. Evidence that hydrogen sulfide exerts antinociceptive effects in the gastrointestinal tract by activating $\mathrm{K}_{\mathrm{ATP}}$ channels. J Pharmacol Exp Ther 316: 325-335, 2006.

15. Distrutti E, Sediari L, Mencarelli A, Renga B, Orlandi S, Russo G, Caliendo G, Santagada V, Cirino G, Wallace JL, and Fiorucci S. 5-Amino-2-hydroxybenzoic acid 4-(5thioxo-5H-[1,2]dithiol-3yl)-phenyl ester (ATB-429), a hydrogen sulfide-releasing derivative of mesalamine, exerts antinociceptive effects in a model of postinflammatory hypersensitivity. J Pharmacol Exp Ther 319: 447-458, 2006.

16. Dufton N and Wallace JL. Phenotypic differences in hydrogen sulfide synthesis and signaling in primary macrophages. Inflammation Res 60: 121, 2011.

17. Ekundi-Valentim E, Santos KT, Camargo EA, DenadaiSouza A, Teixeira SA, Zanoni CI, Grant AD, Wallace J, Muscará MN, and Costa SK. Differing effects of exogenous and endogenous hydrogen sulphide in carrageenan-induced knee joint synovitis in the rat. Br J Pharmacol 159: 1463-1474, 2010.

18. Fiorucci $S$, Antonelli E, Distrutti E, Mencarelli A, Orlandi $S$, Zanardo R, Renga B, Rizzo G, Morelli A, Cirino G, and Wallace JL. Inhibition of hydrogen sulfide generation contributes to gastric injury caused by anti-inflammatory nonsteroidal drugs. Gastroenterology 129: 1210-1224, 2005.

19. Fiorucci S, Mencarelli A, Caliendo G, Santagada V, Distrutti E, Santucci L, Cirino G, and Wallace JL. Enhanced activity of a hydrogen-sulfide releasing mesalamine derivative (ATB429) in a mouse model of colitis. Br J Pharmacol 150: 9961002, 2007.

20. Flannigan KL, McCoy KD, and Wallace JL. Eukaryotic and prokaryotic contributions to colonic hydrogen sulfide synthesis. Am J Physiol Gastrointest Liver Physiol 301: G188-G193, 2011.

21. Furne JK, Suarez FL, Koenig T, DeMaster E, and Levitt MD. Oxidation of hydrogen sulfide and methanethiol to thiolsulfate by rat tissues: a specialized function of the colonic mucosa. Biochem Pharmacol 62: 255-259, 2001.

22. Goubern M, Andriamihaja M, Nübel T, et al. Sulfide, the first inorganic substrate for human cells. FASEB J 21: 1699-1706, 2007.

23. Han W, Dong Z, Dimitropoulou C, Su Y. Hydrogen sulfide ameliorates tobacco smoke-induced oxidative stress and emphysema in mice. Antioxid Redox Signal 15: 2121-2134, 2011.

24. Hosoki R, Matsuki N, and Kimura H. The possible role of hydrogen sulfide as an endogenous smooth muscle relaxant in synergy with nitric oxide. Biochem Biophys Res Commun 237: 527-531, 1997.

25. Jorgensen J and Mortensen PB. Hydrogen sulfide and colonic epithelial metabolism: implications for ulcerative colitis. Dig Dis Sci 46: 1722-1732, 2001.

26. Lagoutte E, Mimoun S, Andriamihaja M, Chaumontet C, Blachier F, and Bouillaud F. Oxidation of hydrogen sulfide remains a priority in mammalian cells and causes reverse electron transfer in colonocytes. Biochim Biophys Acta 1797: 1500-1511, 2010. 
27. Levine J, Ellis CJ, Furne JK, et al. Fecal hydrogen sulfide production in ulcerative colitis. Am J Gastroenterol 93: 83-87, 1998.

28. Levitt MD, Springfield J, Furne J, et al. Physiology of sulfide in the rat colon: use of bismuth to assess colonic sulfide production. J Appl Physiol 92: 1655-1660, 2002.

29. Li L, Rose P, and Moore PK. Hydrogen sulfide and cell signaling. Annu Rev Pharmacol Toxicol 51:169-187, 2011.

30. Li L, Rossoni G, Sparatore A, Lee LC, Del Soldato P, and Moore PK. Anti-inflammatory and gastrointestinal effects of a novel diclofenac derivative. Free Radic Biol Med 42: 706719, 2007.

31. Liu H, Bai XB, Shi S, and Cao YX. Hydrogen sulfide protects from intestinal ischaemia-reperfusion injury in rats. J Pharm Pharmacol 61: 207-212, 2009.

32. Macfarlane GT, Gibson GR, and Cummings JH. Comparison of fermentation reactions in different regions of the human colon. J Appl Bacteriol 72: 57-64, 1992.

33. Magee EA, Richardson CJ, Hughes R, et al. Contribution of dietary protein to sulfide production in the large intestine: an in vitro and a controlled feeding study in humans. Am J Clin Nutr 72: 1488-1494, 2000.

34. Mariggio MA, Minunno V, Riccardi S, Santacroce R, De Rinaldis $\mathrm{P}$, and Fumarulo R. Sulfide enhancement of PMN apoptosis. Immunopharmacol Immunotoxicol 20: 399-408, 1998.

35. Martin GR, McKnight GW, Dicay M, Coffin CS, Ferraz JG, and Wallace JL. Hydrogen sulfide synthesis in the rat and mouse gastrointestinal tract. Dig Liver Dis 42: 103-109, 2010.

36. Martin GR, Perretti M, Flower RJ, and Wallace JL. Annexin-1 modulates repair of gastric mucosal injury. Am J Physiol Gastrointest Liver Physiol 294: G764-G769, 2008.

37. Matsunami M, Tarui T, Mitani K, Nagasawa K, Fukushima O, Okubo K, Yoshida S, Takemura M, and Kawabata A. Luminal hydrogen sulfide plays a pronociceptive role in mouse colon. Gut 58: 751-671, 2009.

38. Moore J, Babidge W, Millard S, et al. Colonic luminal hydrogen sulfide is not elevated in ulcerative colitis. Dig Dis Sci 43: 162-165, 1998.

39. Oh GS, Pae HO, Lee BS, Kim BN, Kim JM, Kim HR, Jeon SB, Jeon WK, Chae HJ, and Chung HT. Hydrogen sulfide inhibits nitric oxide production and nuclear factor-kB via heme oxygenase-1 expression in RAW264.7 macrophages stimulated with lipopolysaccharide. Free Radic Biol Med 41: 106-119, 2006.

40. Papapetropoulos A, Pyriochou A, Altaany Z, Yang G, Marazioti A, Zhou Z, Jeschke MG, Branski LK, Herndon DN, Wang R, and Szabó C. Hydrogen sulfide is an endogenous stimulator of angiogenesis. Proc Natl Acad Sci USA 106: 21972-21977, 2009.

41. Perretti M and D'Acquisto F. Annexin A1 and glucocorticoids as effectors of the resolution of inflammation. Nat Rev Immunol 9: 62-70, 2009.

42. Picton R, Eggo MC, Langman MJ, et al. Impaired detoxification of hydrogen sulfide in ulcerative colitis? Dig Dis Sci 52: 373-378, 2007.

43. Pitcher MC, Beatty ER, and Cummings JH. The contribution of sulphate reducing bacteria and 5-aminosalicylic acid to faecal sulphide in patients with ulcerative colitis. Gut 46: 6472, 2000.

44. Reiffenstein RJ, Hulbert WC, and Roth SH. Toxicology of hydrogen sulfide. Annu Rev Pharmacol Toxicol 32:109-134, 1992.

45. Roediger WE. The colonic epithelium in ulcerative colitis: an energy-deficiency disease? Lancet 2: 712-715, 1980.
46. Roediger WE, Duncan A, Kapaniris O, et al. Sulphide impairment of substrate oxidation in rat colonocytes: a biochemical basis for ulcerative colitis? Clin Sci (Lond) 85: 623627, 1993.

47. Schicho R, Krueger D, Zeller F, et al. Hydrogen sulfide is a novel prosecretory neuromodulator in the guinea-pig and human colon. Gastroenterology 131: 1542-1552, 2006.

48. Searcy DG and Lee SH. Sulfur reduction by human erythrocytes. J Exp Zool 282: 310-322, 1998.

49. Serhan CN, Brain SD, Buckley C, Gilroy DW, Haslett C, O'Neill LA, Perretti M, Rossi AG, and Wallace JL. Resolution of inflammation: state of the art, definitions and terms. FASEB J 21: 325-332, 2007.

50. Shibuya N, Mikami Y, Kimura Y, Nagahara N, and Kimura H. Vascular endothelium expresses 3-mercaptopyruvate sulfurtransferase and produces hydrogen sulfide. J Biochem 146: 623-626, 2009.

51. Suarez F, Furne J, Springfield J, et al. Production and elimination of sulfur-containing gases in the rat colon. Am J Physiol 274: G727-G733, 1998.

52. Theissen U, Hoffmeister M, Grieshaber M, and Martin W. Single eubacterial origin of eukaryotic sulfide:quinone oxidoreductase, a mitochondrial enzyme conserved from the early evolution of eukaryotes during anoxic and sulfidic times. Mol Biol Evol 20: 1564-1574, 2003.

53. Tyagi N, Moshal KS, Sen U, Vacek TP, Kumar M, Hughes WM, Kundu $\mathrm{S}$, and Tyagi SC. $\mathrm{H}_{2} \mathrm{~S}$ protections against methionine-induced oxidative stress in rain endothelial cells. Antiox Redox Signal 11: 25-33, 2009.

54. Wallace JL. Hydrogen sulfide-releasing anti-inflammatory drugs. Trends Pharmacol Sci 28: 501-505, 2007.

55. Wallace JL. Prostaglandins, NSAIDs and mucosal defence. Why doesn't the stomach digest itself? Physiol Reviews 88: 1547-1565, 2008.

56. Wallace JL. Physiological and pathophysiological roles of hydrogen sulfide in the gastrointestinal tract. Antioxid Redox Signal 12: 1125-1133, 2010.

57. Wallace JL. NSAID gastropathy and enteropathy: distinct pathogenesis likely necessitates distinct prevention strategies. Br J Pharmacol, in press.

58. Wallace JL, Caliendo G, Santagada V, and Cirino G. Markedly reduced toxicity of a hydrogen sulfide-releasing derivative of naproxen (ATB-346). Br J Pharmacol 159: 12361246, 2010.

59. Wallace JL, Caliendo G, Santagada V, Cirino G, and Fiorucci S. Gastrointestinal safety and anti-inflammatory effects of a hydrogen sulfide-releasing diclofenac derivative in the rat. Gastroenterology 132: 261-271, 2007.

60. Wallace JL, Dicay M, McKnight W, and Martin GR. Hydrogen sulfide enhances ulcer healing. FASEB J 2007; 21: 4070-4076.

61. Wallace JL, Vong L, McKnight W, Dicay M, and Martin GR. Endogenous and exogenous hydrogen sulphide promotes resolution of colitis in rats. Gastroenterology 137: 569-578, 2009.

62. Wang L and Wallace JL. Hydrogen sulfide reduces cardioautonomic responses to gastric distention (GD) in an ATPsensitive potassium channel (KATP)-dependent manner. Neurogastroenterology and Motility 23(Suppl 1): 18, 2011.

63. Wang R. Two's company, three's a crowd: can $\mathrm{H}_{2} \mathrm{~S}$ be the third endogenous gaseous transmitter? FASEB J 16: 17921798j, 2002.

64. Whiteman M, Armstrong JS, Chu SH, Siau JL, Wong BS, Cheung NS, Halliwell B, and Moore PK. The novel 
neuromodulator hydrogen sulfide: an endogenous peroxynitrite scavenger? J Neurochem 90: 765-768, 2004.

65. Whiteman M, Cheung NS, Zhu YZ, Chu SH, Siau JL, Wong BS, Armstrong JS, and Moore PK. Hydrogen sulphide: a novel inhibitor of hypochlorous acid-mediated oxidative damage in the brain? Biochem Biophys Res Commun 326: 794-798, 2005.

66. Whiteman M, Haigh R, Tarr JM, Gooding KM, Shore AC, and Winyard PG. Detection of hydrogen sulfide in plasma and knee-joint synovial fluid from rheumatoid arthritis patients: relation to clinical and laboratory measures of inflammation. Ann NY Acad Sci 1203: 146-150, 2010.

67. Whiteman M, Li L, Rose P, Tan CH, Parkinson DB, and Moore PK. The effect of hydrogen sulfide donors on lipopolysaccharide-induced formation of inflammatory mediators in macrophages. Antioxid Redox Signal 12: 1147-1154, 2010.

68. Xu XM, Yu JP, He XF, Li JH, Yu LL, and Yu HG. Effects of garlicin on apoptosis in rat model of colitis. World J Gastroenterol 11: 4579-4582, 2005.

69. Xu ZS, Wang XY, Xiao DM, Hu LF, Lu M, Wu ZY, and Bian JS. Hydrogen sulfide protects MC3T3-E1 osteoblastic cells against $\mathrm{H}_{2} \mathrm{O}_{2}$-induced oxidative damage - implications for the treatment of osteoporosis. Free Radic Biol Med 15: 13141323, 2011.

70. Zamuner SR, Bak AW, Devchand PR, and Wallace JL. Predisposition to colorectal cancer in rats with resolved colitis: role of COX-2-derived PGD 2 . Am J Pathol 167: 1293-1300, 2005.

71. Zamuner SR, Warrier N, Buret AG, MacNaughton WK, and Wallace JL. Cyclooxygenase 2 mediates post-inflammatory colonic secretory and barrier dysfunction. Gut 52: 1714-1720, 2003.

72. Zanardo RCO, Brancaleone V, Distrutti E, Fiorucci S, Cirino $\mathrm{G}$, and Wallace JL. Hydrogen sulphide is an endogenous modulator of leukocyte-mediated inflammation. FASEB J 20: 2118-2120, 2006.

73. Zhao $\mathrm{W}$ and Wang $\mathrm{R}$. $\mathrm{H}_{2} \mathrm{~S}$-induced vasorelaxation and underlying cellular and molecular mechanisms. Am J Physiol 283: H474-H480, 2002.

74. Zhao W, Zhang J, Lu Y, and Wang R. The vasorelaxant effects of $\mathrm{H}_{2} \mathrm{~S}$ as a novel endogenous gaseous $\mathrm{K}_{\text {ATP }}$ channel opener. EMBO J 20: 6008-6016, 2001.
75. Zhong GZ, Chen RF, Cheng YQ, Tang CS, and Du JB. The role of hydrogen sulfide generation in the pathogenesis of hypertension in rats induced by inhibition of nitric oxide synthase. J Hypertens 21: 1879-1885, 2003.

76. Zuidema MY, Yang Y, Wang M, Kalogeris T, Liu Y, Meininger CJ, Hill MA, Davis MJ, and Korthuis RJ. Antecedent hydrogen sulfide elicits an anti-inflammatory phenotype in postischemic murine small intestine: role of BK channels. Am J Physiol Heart Circ Physiol 299: H1554H1567, 2010.

Address correspondence to: Dr. John L. Wallace

Farncombe Digestive Health Research Institute McMaster University 1280 Main Street West Hamilton, Ontario, L8S 4K1

Canada

E-mail: jwalla@mcmaster.ca

Date of first submission to ARS Central, October 19, 2011; date of acceptance, October 22, 2011.

$\begin{aligned} & \text { Abbreviations Used } \\ \mathrm{AnxA}-1 & =\text { annexin- } 1 \\ \mathrm{AMP} & =\text { adenosine monophosphate } \\ \mathrm{CBS} & =\text { cystathionine-beta-synthase } \\ \mathrm{COX} & =\text { cyclooxygenase } \\ \mathrm{CSE} & =\text { cystathionine-gamma-lyase } \\ \mathrm{IL} & =\text { interleukin } \\ \mathrm{iNOS} & =\text { inducible nitric oxide synthase } \\ \mathrm{NF}-\kappa \mathrm{B} & =\text { nuclear transcription factor- } \kappa \mathrm{B} \\ \mathrm{NSAID} & =\text { nonsteroidal anti-inflammatory drug } \\ \mathrm{PGE} & =\text { prostaglandin } \mathrm{E}_{2} \\ \mathrm{PMN} & =\text { polymorphonuclear leukocyte } \\ \mathrm{TNF} & =\text { tumor necrosis factor }\end{aligned}$

